\title{
EFFECT OF LOW-LEVEL LASER THERAPY COMBINED WITH CONVENTIONAL PHYSIOTHERAPY ON PAIN AND QUALITY OF LIFE IN PATIENTS WITH MYOFASCIAL PAIN DYSFUNCTION SYNDROME
}

\author{
Ahmed Tarek Mostafa El-sharkawy* and Rehab El-Saeed El-Sherbeeny Ahmad **
}

\begin{abstract}
Background: Temporomandibular Joint Disorders (TMDs) are considered the most common chronic orofacial pain conditions. It is characterized by pain in the Temporomandibular Joint (TMJ) area, masticatory muscles and associated musculoskeletal structures with the affection of mouth opening. Conventional physiotherapy and Low-Level LASER Therapy (LLLT) are safe and noninvasive modalities that each therapist focuses on to relieve pain and increase the quality of life.
\end{abstract}

Aim: The aim of this study was to investigate the effect of low-level LASER therapy combined with conventional physiotherapy on pain and quality of life in patients with Myofascial pain dysfunction syndrome (MPDS).

Methods: 60 patients (45 females and 15 males) with MFDS of TMJ were divided randomly into study and control groups. The study group received conventional physiotherapy consisting of active and stretching exercises for mandibular muscles with ultrasound and LLLT application on TMJ area. Control group received conventional physiotherapy only. Pressure pain threshold was evaluated using hand-held pressure algometer and quality of life was evaluated using the World Health Organization Quality of Life (WHOQOL-BREF) assessment instrument at baseline and 4 weeks after the treatment.

Results: There was a significant increase $(p<0.05)$ in the quality of life, with a significant increase $(\mathrm{p}<0.05)$ in pressure pain threshold for TMJ, masseter and anterior temporalis muscles at both sides in the study group compared with control group.

Conclusion: The combination of conventional therapy with LLLT was more effective in pain relief and improvement of the quality of life than the conventional therapy alone for patients with MPDS.

KEYWORDS: Temporomandibular joint, Physiotherapy, Low-level LASER therapy, Myofascial pain dysfunction syndrome.

* Department of Oral and Maxillofacial Surgery, Faculty of Dentistry, Cairo University, Egypt

** Department of Basic Science, Faculty of Physical Therapy, October 6 University, Egypt 


\section{INTRODUCTION}

Temporomandibular joint dysfunction (TMD) is a collective term that includes disorders of the Temporomandibular Joint (TMJ), the masticatory muscles and their associated structures. The most common symptoms are pain, restricted mandibular movement, and clicking, popping, or grating sounds in the jaw joint. Pain can be temporary or last many years with one or both sides of face affection ${ }^{[1]}$. Although TMDs is not life-threatening, they can be detrimental to the quality of life because the symptoms can become chronic and difficult to manage ${ }^{[2]}$. About $20-30 \%$ of the adult populations are affected to some degree. Usually, people affected by TMD are between 20 and 40 years of age and it is more common in females than males ${ }^{[3]}$. TMDs are the second most frequent cause of orofacial pain after dental pain. The etiology is currently known to be multifactorial, including the presence of para-functional habits, trauma, stress, as well as emotional, systemic, hereditary, and occlusal factors ${ }^{[4]}$. The etiology is related to an association of predisposing factors that include other pain conditions (e.g., chronic headaches), fibromyalgia, autoimmune disorders, sleep apnea, and psychiatric illness. These factors increase the risk of TMDs ${ }^{[5]}$. Epidemiological studies showed that about $75 \%$ of the population presents one sign of TMD and $35 \%$ present at least one symptom, however, only a minor percentage of the population (3-7\%) presents problems severe enough to look for treatment for TMJDs ${ }^{[6]}$. Non-surgical treatment of TMDs generally consists of medication, such as Non-Steroidal AntiInflammatory Drugs (NSAIDs) and antidepressants, splint therapy or/and physiotherapy. NSAIDs may reduce the inflammation and swelling but may also increase the risk of complications, such as gastric ulcer and nephrotoxicity ${ }^{[7]}$. Physical therapy is an especially important part of recovery from TMDs, as it helps minimize adhesion formation and muscle tightness through its analgesic, myorelaxing, anti-inflammatory and stimulations effects. Low-
Level LASER Therapy (LLLT) is an option for the treatment of musculoskeletal disorders; its' advantages include easy application, limited treatment time and minimum contraindications, due to its analgesic, anti-inflammatory and regenerative effects ${ }^{[8]}$. Exercises play an important role in increasing muscle strength and coordination and improving mouth function ${ }^{[7]}$. It was hypothesized that there was no effect of conventional therapy in combination to LLLT on the treatment of TMDs. Therefore, the purpose of this study was to investigate the effect of conventional therapy and low-level LASER therapy on pain and limitations of daily functions in patients with TMD.

\section{PATIENTS AND METHODS}

Subjects: This prospective study was conducted on 60 patients of both genders (45 females and 15 males) with MPDS of TMJ in the Department of Physical Therapy at October 6 University Hospital from December 2016 to October 2017. All participants signed a written consent. The study was approved by the ethical committee of the Faculty of Physical Therapy.

Randomization: was performed simply by asking the patient to choose a piece of paper in which (A) or (B) letters were written. (A) was considered group (I) which received LLLT in addition to conventional physiotherapy, while (B) was considered group (II) which received only conventional physiotherapy (control group). The patients were selected to be enrolled in this study according to the following criteria:

\section{Inclusive criteria:}

1. Patient age ranged from $20-60 \mathrm{y}$.

2. Pain in masticatory muscles or TMJ for at least 3 months in accordance with the Research Diagnostic Criteria for Temporomandibular Disorders (RDC/TMD). 


\section{Exclusive criteria:}

1. Presence of systematic musculo-articular pathologies.

2. Pregnant women.

3. History of facial trauma.

4. Facial palsy.

5. Fractures of the facial bones.

Design of the study: The study was a randomized controlled trial. Patients who fulfilled the inclusion criteria were randomly assigned into two groups. The study group received conventional therapy and LLLT. Control group received conventional therapy only. The evaluation procedure had been done for all patients in the two groups before starting the program and after 4 weeks of treatment.

Instruments for evaluating Pressure pain threshold: Pressure Pain Threshold (PPT) was determined using a hand-held pressure algometer that responds linearly to force application between 0 and $10 \mathrm{~kg}(22 \mathrm{lb} \times 0.25 \mathrm{lb}$ and $10 \mathrm{~kg} \times 100 \mathrm{~g})$. It has a $1 \mathrm{~cm}^{2}$ round rubber tip to minimize irritation of the skin, and values are displayed as the maximum force applied before the individual verbally states that the pain threshold has been reached. The handheld pressure algometer is a reliable method to assess the PPT ${ }^{[9]}$.

The quality of life was assessed using World Health Organization Quality of Life (WHOQOLBREF) assessment instrument that comprises 26 question in the domains of physical health, psychological health, social relations ships, and the environment. Each question have five answers, the patient will choose the answer that will appear most appropriate, if the patient is confused about the answer its advised that the first response comes to mind is the best answer, the answers will be according to a numerical scale from (1-5) 1 for very poor and 5 for very good Using the $0-100$ scale scores in effect size calculations (effect size, 95\% confidence interval), (Appendix I, II).
Instruments for treatment: Low-level LASER device: LLLT was performed by MLS® LASER Therapy (ASA Srl, Vicenza, Italy). Its' average power is up to $1.1 \mathrm{~W}$, class IV IR LASER with two synchronized sources (LASER diodes). The two modules have different wavelengths, peak power, and emission mode. The first one is a pulsed LASER diode, emitting at $905 \mathrm{~nm}$, with peak optical power $25 \mathrm{~W}$; each pulse is composed of a pulse train (single pulse width $100 \mathrm{~ns}$, maximum frequency 90 $\mathrm{kHz}$ ), thus varying the average power delivered to the tissue. The frequency of the pulse trains may be varied in the range of 1-2000 Hz. The second laser diode $(808 \mathrm{~nm}$ ) operates in continuous mode (power $1.1 \mathrm{~W}$ ) or in pulsed mode (pulses repetition rate 1-2000 Hz), mean optical power output $550 \mathrm{~mW}$, duty ratio $50 \%$ independently of the pulse repetition rate. The probe was placed behind, in front of, and above the mandibular condyle, and into the external auditory meatus, with the following parameters: Pulse rate: 1500 Hz, Pulse duration: 100 ns, Energy density: $16 \mathrm{~J} / \mathrm{cm} 2$, LASER beam diameter: $3.14 \mathrm{~cm}^{2}$ and Duration: 14 second for each point. (Fig.1)

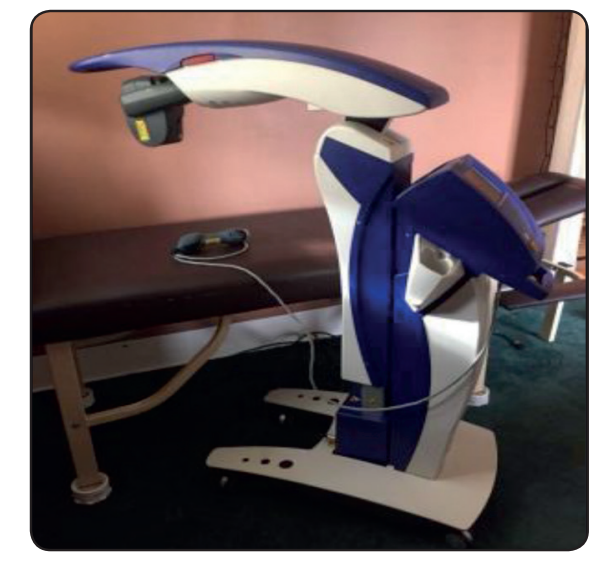

Fig. (1) A photograph showing the LLLT device

Ultrasound device: Phyaction $\mathrm{Ub}$ was used in the area of TMJ and masticatory muscles (Gymna Uniphy, GY336600, and Italy).

The Moist heat pack: Half size $(13 \times 30 \mathrm{~cm})$ hot pack applied to the area around the TMJ and masticatory muscles for $10 \mathrm{~min}$. 
Assessment procedures: Each patient was assessed before and after 4 weeks (at the end of the treatment) for both groups. The assessment includes oral history and physical examination. (a) Oral history: The oral history was always taken by the examiner and included questions on pain in the orofacial region. When the pain was present, its location, nature, duration, and radiation were determined. Moreover, aggravation of pain on the function of the masticatory system was noted. After the history taking, the subjects were asked to choose any one of five levels on a numerical rating scale from "no problem at all" (0) to "extremely difficult" (4 points). (b) Physical examination: Include pressure algometry. During this test, the subject was seated in an upright position and was asked to relax the muscles with the teeth apart. The subject's head was supported by a headrest. PPT was measured once at TMJ, masseter muscles and anterior temporalis muscles on both sides in a relaxed posture.

Treatment Procedure: Patients in both groups received ultrasound application, hot pack application and exercise program, in three sessions per week for 4 weeks in addition to LLLT for the study group.

\section{Exercise program}

1. Active exercises for mandibular muscles: Active exercises were used to correct the mouth opening in the form of (A) Lateral motion towards the right and the left side, protrusion and wide mouth opening. The patients performed these exercises 3 sets with 10 repetitions in each set.

(B) Relaxed jaw exercise: The tongue gently rested on the top of the mouth behind the upper front teeth. The teeth come apart while relaxing the jaw muscles.

(C) Chin tucks: The patient pulled his/her chin straight back with the shoulders back, creating a "double chin." This position was held for three seconds and repeated 10 times.
(D) The resisted opening of the mouth: The patient placed the thumb under the chin and asked to open the mouth slowly and pushing gently against the chin for resistance. Hold for 3 to $6 \mathrm{~s}$, and then close the mouth slowly.

(E) The resisted closing of the mouth: The patient asked to squeeze the chin with the index and the thumb with one hand and to close the mouth as placing gentle pressure on the chin. This exercise applied for 3 sets with 10 repetitions in each set.

2. Stretching exercise for mandibular muscles: the patient was asked to open the mouth by pushing simultaneously the thumb against the upper anterior teeth and forefinger against the lower anterior teeth for 4 sets per session. The single set included 3 cycles of stretching, each cycle lasted 30s.

\section{Statistical analysis:}

All statistical measures were performed through the Statistical Package for Social Studies (SPSS) version 22 for windows. The current test involved two independent variables. The first one was the (tested group); a between-subject factor which had two levels (study group receiving conventional therapy consisting of active movements and stretching exercise with ultrasound and LLLT application and control group receiving conventional therapy only). The second one was the (training periods); a within-subject factor which had two levels (pretreatment and post-treatment). In addition, this test involved seven tested dependent variables (Pressure pain threshold for TMJ, Masseter and Anterior temporalis muscles at both sides, and quality of life scale). Prior to final analysis, data were screened for normality assumption and the presence of extreme scores. Descriptive analysis using histograms with the normal distribution curve showed that the data were normally distributed and not violates the parametric assumption for the all dependent variables. Additionally, testing for the homogeneity 
of covariance using Box's test revealed that there was no significant difference with $\mathrm{p}$ values of $>0.05$. Normality test of data using the ShapiroWilk test was used, that reflected the data was normally distributed for the all dependent variables. Accordingly, $2 \times 2$ mixed design MANOVA was used to compare the tested variables of interest at different tested groups and training periods. The MANOVAs were conducted with the initial alpha level set at 0.05 . To determine the similarity of both groups at baseline, subject age, height and body weight were compared using independent t-tests.

Sample size To avoid a type II error, a preliminary power analysis (power $(1-\alpha$ error $P)=0.85, \alpha=0.05$, effect size ( $f 2 v=0.2$, Pillai $V=0.33)$, determined a sample size of 30 for each group in this study. This effect size was calculated according to a pilot study on 12 participants ( 6 in each group) considering all dependent variables as a primary outcome.

\section{RESULTS}

As indicated by the independent t-test, there were no statistically significant differences $(\mathrm{P}>0.05)$ between subjects in both groups concerning age, weight, and height (Table 1). Statistical analysis using mixed design MANOVA analyzed 60 patients assigned into two equal groups. It revealed that there were significant within-subject $(\mathrm{F}=742.633$, $\mathrm{p}=0.000)$, treatment time $(\mathrm{F}=100.87, \mathrm{p}=0.000)$, and between subject $(\mathrm{F}=25.892, \mathrm{p}=0.000)$.

However, there were significant increases $(\mathrm{p}<0.05)$ in pressure pain threshold for (TMJ, masseter and anterior temporalis muscles at both sides) in the post-treatment compared with the pre-treatment in both groups (Table 2). Regarding betweensubject effects, multiple pairwise comparisons revealed that there was a significant increase $(p<0.05)$ in pressure pain threshold for TMJ, masseter and anterior temporalis muscles at both sides in the study group compared with control group.

Regarding Quality of Life Questionnaire (WHOQOL-BREF); Multiple pairwise comparison tests (Post hoc tests) revealed that there was a significant reduction of Physical health domains score at post-treatment compared with pre-treatment (P-value $=0.0001)$. While multiple pairwise comparison tests (Post hoc tests) revealed that there was no significant difference of the mean values of the "post" test between group (A) and (B) with $\mathrm{p}=0.259$. The same applied to Psychological health domains score, Social relations health domains score, and Environmental domains score.

TABLE (1) Table representing Physical characteristics of participants in both group (A) and (B).

\begin{tabular}{|c|c|c|c|c|c|}
\hline \multirow{2}{*}{ Items } & Group (A) & \multicolumn{2}{|c|}{ Group (B) } & \multicolumn{2}{|c|}{ Comparison } \\
\cline { 2 - 5 } & Mean \pm SD & Mean \pm SD & t-value & P-value \\
\hline Age (years) & $37.56 \pm 8.26$ & $37.03 \pm 6.26$ & 0.282 & 0.779 & NS \\
\hline Body mass (Kg) & $84.66 \pm 2.89$ & $83.93 \pm 3$ & 0.963 & 0.34 & NS \\
\hline Height (cm) & $165.96 \pm 2.49$ & $166.73 \pm 2.89$ & -1.097 & 0.277 & NS \\
\hline
\end{tabular}

*SD: standard deviation, P: probability, S: significance, NS: non-significant. 
TABLE (2) Table representing Descriptive statistics for pressure pain threshold for TMJ, masseter and anterior temporalis muscles at both sides

\begin{tabular}{|c|c|c|c|c|}
\hline & \multicolumn{2}{|c|}{ Study group } & \multicolumn{2}{c|}{ Control group } \\
\hline Variables & Pre Post & Prest \\
\hline Right TMJ & $1.87 \pm 0.43$ & $3.29 \pm 0$. & $1.90 \pm 0$. & $2.45 \pm 0.25$ \\
\hline Right masseter muscle & $2.61 \pm 0.25$ & $3.75 \pm 0.18$ & $2.64 \pm 0.19$ & $3.18 \pm 0.19$ \\
\hline Right anterior temporalis & $4.11 \pm 0.24$ & $4.7 \pm 0.18$ & $4.23 \pm 0.20$ & $2.54 \pm 0.19$ \\
\hline Left TMJ & $0.231 .89 \pm$ & $0.33 \pm 2.96$ & $1.91 \pm 0.19$ & $3.19 \pm 0.26$ \\
\hline Left masseter muscle & $2.71 \pm 0.22$ & $3.71 \pm 0.16$ & $2.79 \pm 0.1$ & $4.56 \pm 0.21$ \\
\hline Right anterior temporalis & $4.30 \pm 0.19$ & $4.78 \pm 0.16$ & $4.33 \pm 0.21$ & 2.36 \\
\hline
\end{tabular}

\section{DISCUSSION}

The current study investigated the effect of conventional physiotherapy and low-level LASER therapy on pain and Quality of life in patients with MPDS. Pressure pain threshold was evaluated using hand-held pressure algometer and quality of life was evaluated by the Quality of Life Questionnaire (WHOQOL-BREF) at baseline and the 4 weeks after the treatment.

The result of this study showed that there were significant increases $\quad(\mathrm{p}<0.05)$ in pressure pain threshold for TMJ, masseter and anterior temporalis muscles at both sides in the post-treatment compared with the pre-treatment in both groups. This may be matched with the result of the previous studies that investigate the effect of the combination of the US, manual therapy, LLLT, patient education and occlusal splints on the treatment of TMJDs ${ }^{[11,12]}$. These studies recommended that the aim of the treatment of patients with TMDs should be considered from different aspects to control pain due to several factors affecting the etiology of TMDs ${ }^{[10]}$.

Gray et al. evaluated the effectiveness of several modalities such as short-wave diathermy, US, and LASER treatments for patients with TMDs and they found that no method was superior to the others in changing PPT values and that these modalities were significantly better than placebo treatment ${ }^{[13]}$. Also, Mohl et al. stated that the US alone has no significant effect on increasing PPT values in TMDs in trials ${ }^{[14]}$. Increasing PPT values due to the application of exercise in agreeing with the study of Mehmet et al. 2014, who stated that the combination between the US and a home exercise program may improve the symptoms of patients with TMDs; this improvement may attribute to the reduction of inflammation, promotion of muscular relaxation, and increase in blood flow ${ }^{[15]}$. Previous studies ${ }^{[11-13]}$ demonstrated that stretching exercises, isometric tension, and relaxation exercises with educational instruction are effective in increasing PPT values in TMDs and mouth opening and improving mandibular movements. Nicolakis et al. revealed that exercise therapy reduces pain in $80 \%$ of cases and improves the range of motion in $75 \%$ of closed lock patients. This indicates that exercise therapy is significantly more effective than placebo ${ }^{[16]}$. Yoshida et al. found that performing Mandibular Condylar Movement Exercise (MCME) eight times per day increases PPT values and the range of mouth opening in closed lock cases ${ }^{[17]}$. 
Regarding thermotherapy in TMDs, a study was conducted with 27 patients with TMDs symptoms and muscle impairment found that symptoms of pain were reduced in $34.7 \%$ of patients of the study group (occlusal splint and thermotherapy) and only in $3.75 \%$ of patients in control group (occlusal splint only) ${ }^{[18]}$. In a recent study on sixty patients with chronic low back dysfunction. The author found that the combination of exercises, thermotherapy, and ultrasound in the session have an effective role in decreasing pain severity and functional disability in these cases. This agrees with the result of the conventional therapy group ${ }^{[19]}$.

The effect of LLLT on pain intensity was demonstrated in previous studies by Ahrari et al. (pulsed $810 \mathrm{~nm}$, average power $50 \mathrm{~mW}$, peak power $80 \mathrm{~W}, 1500 \mathrm{~Hz}, 120 \mathrm{~s}, 6 \mathrm{~J}$, and $3.4 \mathrm{~J} / \mathrm{cm} 2$ per point) and Menezes et al. ${ }^{[20,21]}$ (gallium- aluminumarsenide; $\lambda=830 \mathrm{~nm}, \mathrm{P}=40 \mathrm{~mW}, \mathrm{CW}, \mathrm{ED} 08 \mathrm{~J} / \mathrm{cm} 2$ ), who all found a statistically significant improvement in PPT values of TMDs. The findings of this study are in agree with Hamid et al. study who concluded that LLLT caused a significant improvement in mouth opening and PPT values in patients with MPDS ${ }^{[22]}$. Also in agreeing with Fikácková study who suggest that LLLT (application of $10 \mathrm{~J} /$ $\mathrm{cm} 2$ and $15 \mathrm{~J} / \mathrm{cm} 2$ ) can be considered as a useful method in decreasing pain related to TMDs [23]. This improvement may be attributed to increasing of lymphatic flow that reduces edema and causes a decrease of prostaglandin E2 and cyclooxygenase-2 levels after application of LLLT ${ }^{24]}$.

In contrast, the findings of this study disagree with Emshoff et al. ${ }^{[6]}(632.8 \mathrm{~nm}, 30 \mathrm{~mW}, 1.5 \mathrm{~J} / \mathrm{cm} 2)$, Carrasco et al. ${ }^{[25]}(780 \mathrm{~nm}, 50 / 60 / 70 \mathrm{~J} / \mathrm{cm} 2)$ and da Cunha et al. ${ }^{[26]}(830 \mathrm{~nm}, 500 \mathrm{Mw}, 100 \mathrm{~J} / \mathrm{cm} 2)$, who reported that there was no difference between both laser and placebo groups in pain reduction.

Regarding the application of ultrasound with exercises and LLLT; this study results agree with the study of Grieder et al. ${ }^{[27]}$ who suggested that the ultrasonic therapy was less effective in relieving symptoms of TMDs; however, it is more effective when used in combination with other modalities of therapy. Also, Esposito et al. ${ }^{[28]}$ concluded that ultrasound is less effective in reducing symptoms associated with the disk and most successful in relieving muscle symptoms. Esenyel et al. ${ }^{[2]}$ concluded that ultrasound treatment and trigger point injections were found to be equally effective in relieving symptoms of TMDs. In the same context, Majlesi et al. ${ }^{[30]}$ stated that high-power ultrasound applied before stretching the muscle with the trigger points were more effective $(\mathrm{P}<0.05)$ than conventional ultrasound in reducing limitations associated with daily functions. This may be attributed to the thermal effects of the U.S. ${ }^{[31]}$.

Regarding the effect of heat on TMJ dysfunction, a study found that superficial moist heat in combination with occlusal splint was more effective to reduce pain-related limitations in daily functions than the splint group ${ }^{[18]}$. Another study compared the effectiveness of an electric heating pad and moistened towel on acute muscular TMDs with guidelines regarding removal of harmful oral habits and restricted diet. The results revealed that the mouth opening increase with relief of symptoms of limitations in daily functions ${ }^{[32]}$. Nozaki et al. reported that the use of thermotherapy followed by massages on the masseter muscle, upward and downward, with both hands, 24 times per min increase the bite force in patients with TMDs ${ }^{[33]}$. Muhtaroğullari et al. performed a treatment program consisting of active ROM and stretching exercise for 5 times per day for $5 \mathrm{~min}$ and after a 6 -month period of treatment, he found that all patients reported a beneficial improvement in mouth opening and limitations in daily functions ${ }^{[34]}$. Also, Tegelberg ${ }^{[35]}$ found that there was a significant improvement in the TMJ mobility after physical training, while $\mathrm{Au}$ ${ }^{[36]}$ has observed that joint clicks have disappeared in most of the patients after strengthening and stretching exercise program. However, exercise therapy has not shown to be equally effective in improvement of symptoms such as pain and locking. 
The results of this study showed that LASER therapy was efficient in promoting an increase of mandibular movements in the patients who received the low- level LASER dose $(15 \mathrm{~J} / \mathrm{cm} 2)$. This may be due to the analgesic effect of low-level LASER therapy especially with $905 \mathrm{~nm}$ pulsed wavelength on the selected points that considering the presence of nociceptors in the peri-articular tissues (ligaments, capsule, and retrodiscal tissues) because these structures are involved in TMJ pain ${ }^{[37]}$. Marini et al. postulated that mandibular function improved in all patients who received LLLT and it has been more efficient in the treatment of pain and decrease of movement caused by TMDs compared to ibuprofen ${ }^{[38]}$. Also, Simel et al. suggested that LLLT is an appropriate treatment for TMDs related pain and limited mouth opening ${ }^{[39]}$. This may attribute to the great value of LASERs in increasing of the beta-endorphin level, increasing of pain discharge threshold, decreasing of bradykinin and histamine release, increasing of lymphatic flow, decreasing of edema and analgesic substances, increasing of blood supply, reduction of inflammation, and promotion of muscle relaxation ${ }^{[40]}$. Improvement of TMJ functions in TMJDs after application of LLLT may be due to the stimulation of cellular respiratory chain in the mitochondria that induces increased vascularization and fibroblast formation. LLLT not only affects the blood microcirculation but also increases Adenosine Triphosphate (ATP) production ${ }^{[24]}$.

It was noticed that firm clenching of the teeth and using the jaw for a long period during meals have a temporary relief in pain. This may be due to long compression on TMJ component that leads to mechanical disruption of the joint. The results of this study disagree with Emshoff et al. ${ }^{[6]}$ and Venancio et al. studies ${ }^{[5]}$ who all reported that there was no improvement of pain and mouth opening in TMDs after the application of LLLT. Also, Petrucci et $\mathrm{al}^{[41]}$ reported that LLLT is inadequate in reducing chronic TMJ pain and improve functional disability related to TMDs.

\section{CONCLUSION}

The results of the study confirmed that the combination of conventional therapy with LLLT was effective in the improvement of PPT values of TMDs and promoted a significant reduction of pain symptoms related to the quality of life.

\section{REFERENCES}

1. Cascos-Romero J, Vazquez-Delgado E, Vazquez- Rodriguez E, Gay-Escoda C. The use of tricyclic antidepressants in the treatment of temporomandibular joint disorders: a systematic review of the literature of the last 20 years. Med Oral Patol Oral Cir Bucal 14: 37, 2009.

2. Guo C, Shi Z, Revington P. Arthrocentesis and lavage for treating temporomandibular joint disorders. Cochrane Database Syst Rev 7: 4, 2009.

3. Edwab RR. Essential dental handbook: clinical and practice management advice from the experts. Tulsa, Penn Well 251-309, 2003.

4. Kato MT, Kogawa EM, Santos CN, Conti PC. TENS and low-level laser therapy in the management of temporomandibular disorders. J Appl Oral Sci 14: 130$135,2006$.

5. Venancio Ryde A, Camparis CM, Lizarelli Ryde F. Low-intensity LASER therapy in the treatment of temporomandibular disorders: a double-blind study. J Oral Rehabil 32: 800-807, 2005.

6. Emshoff R, Bosch R, Pumpel E, Schoning H, Strobl H. Lowlevel LASER therapy for treatment of temporomandibular joint pain: a double-blind and placebo-controlled trial. Oral Surg Oral Med Oral Pathol Oral Radiol Endod 105: 452-456, 2008.

7. Carvalho CM, de Lacerda JA, dos Santos Neto FP, Cangussu MC, Marques AM, Pinheiro AL. Wavelength effect in temporomandibular joint pain: a clinical experience. LASERs Med Sci 25: 229-232, 2010.

8. Kulekcioglu S, Sivrioglu K, Ozcan O, Parlak M. Effectiveness of low-level LASER therapy in temporomandibular disorder. Scand J Rheumatol 32: 114-118, 2003.

9. Mutlu EK, Ozdincler AR. Reliability and responsiveness of algometry for measuring pressure pain threshold in patients with knee osteoarthritis. J Phys Ther Sci 27: 1961$1965,2015$. 
10. Liu F, Steinkeler A. Epidemiology, diagnosis, and treatment of temporomandibular disorders. Dent Clin North Am 57: 465-479, 2013.

11. Okeson JP. Orofacial pain: guidelines for assessment, diagnosis, and management. Quintessence, Chicago 1996.

12. Tuncer AB, Ergun N, Tuncer AH, Karahan S. Effectiveness of manual therapy and home physical therapy in patients with temporomandibular disorders: A randomized controlled trial. J Bodyw Mov Ther 17: 302-308, 2013.

13. Gray RJ, Quayle AA, Hall CA, Schofield MA. Physiotherapy in the treatment of temporomandibular joint disorders: a comparative study of four treatment methods. Br Dent $\mathrm{J}$ 176: 257-261, 1994.

14. Mohl ND, Ohrbach RK, Crow HC, Gross AJ. Devices for the diagnosis and treatment of temporomandibular disorders. Part III: Thermography, ultrasound, electrical stimulation, and electromyographic biofeedback. J Prosthet Dent 63: 472-477, 1990.

15. Mehmet U, Ümit S, İran K, Selma E, Alparslan Y, Ahmet T, Ahmet B. Effectiveness of a home exercise program in combination with ultrasound therapy for temporomandibular joint disorders. J Phys Ther Sci 26: 1847-1849, 2014.

16. Nicolakis P, Erdogmus B, Kopf A, Ebenbichler G, Kollmitzer J, Piehslinger E, Fialka-Moser V. Effectiveness of exercise therapy in patients with internal derangement of the temporomandibular joint. J Oral Rehabil 28: 1158$1164,2001$.

17. Yoshida H, Kashiwagi K, Sakata T, Tanaka M, Kawazoe T, Morita S. Prognostic factor of mandibular condylar movement exercise for patients with internal derangement of the temporomandibular joint on initial presentation: Preliminary report. J Cranio Maxillofac Surg 41: 356-358, 2013.

18. Nelson SJ, Ash MM. An evaluation of a moist heating pad for the treatment of $\mathrm{TMJ} / \mathrm{muscle}$ pain dysfunction. Cranio 6: 355-359, 1988.

19. Emad Eldin MAEI. Conventional therapy versus positional release technique in the treatment of chronic low back dysfunction. Int J Physiother Res 5: 2325-2331, 2017.

20. Ahrari F, Madani AS. The efficacy of low-level LASER therapy for the treatment of the myogenous temporomandibular joint disorder. LASERs Med Sci 29: 551-557, 2014.
21. Salmos-Brito JA, Menezes RF. Evaluation of low level LASER therapy in patients with acute and chronic temporomandibular disorders. LASERs Med Sci 28: 57-64, 2013.

22. Hamid Reza K, Fahimeh A, Jamileh BT, Sedigheh B, Zahra N, Firoz P. Effect of low-power LASER on the treatment of orofacial pain. J Dent Res Dent Clin Dent Prospect 4: 75-78, 2010.

23. Fikácková H, Dostálová T, Navrátil L, Klaschka J. Effectiveness of low-level LASER therapy in temporomandibular joint disorders: a placebo-controlled study. Photomed LASER Surg 25: 297-303, 2007.

24. Melis M, Di Gioia M, Zawawi KH. Low-level LASER therapy for the treatment of temporomandibular disorders: a systematic review of the literature. Cranio 30: 304-312, 2012.

25. Carrasco TG, Mazzetto MO, Mazzetto RG, Mestriner W Jr. Low intensity LASER therapy in temporomandibular disorder: a phase II double-blind study. Cranio 26: 274 $281,2008$.

26. da Cunha LA, Firoozmand LM, da Silva AP. Efficacy of low level LASER therapy in the treatment of temporomandibular disorder. Int Dent J 58: 213-217, 2008.

27. Grieder A, Vinton PW, Cinotti W, Kangur TT. An evaluation of ultrasonic therapy for temporomandibular joint dysfunction. Oral Surg Oral Med Oral Pathol 31: 25-31, 1971.

28. Esposito CJ, Veal SJ, Farman AG. Alleviation of myofascial pain with ultrasonic therapy. J Prosthet Dent 51: 106-108, 1984.

29. Esenyel M, Caglar N, Aldemir T. Treatment of myofascial pain. Am J Phys Med Rehabil 79: 48-52, 2000.

30. Majlesi J, Unalan H. High-power pain threshold ultrasound technique in the treatment of active myofascial trigger points: A randomized, double-blind, case-control study. Arch Phys Med Rehabil 85: 833-836, 2004.

31. Ter Haar G. Therapeutic ultrasound. Eur J Ultrasound 9: 3-9, 1999.

32. Nelson SJ, Santos JJ, Barghi N, Narendran S. Using moist heat to treat acute temporomandibular muscle pain dysfunction. Compendium 12: 808-816, 1991.

33. Nozaki S, Kawai M, Shimoyama R, Futamura M, Matsumura T, Adachi K, Kikuchi Y. Range of motion exercise of temporomandibular joint with hot pack increases occlusal force in patients with Duchenne muscular dystrophy. Acta Myol 29: 392-397, 2010. 
34. Muhtaroğullari M, Ertan AA, Demiralp B, Canay S. Correlation between clinical and magnetic resonance imaging findings in the treatment of anterior disc displacement. Int J Prosthodont 26: 138-142, 2013.

35. Tegelberg A, Kopp S. Short-term effect of physical training on temporomandibular joint disorder in individuals with rheumatoid arthritis and ankylosing spondylitis. Acta Odontol Scand 46: 49-56, 1988.

36. Au AR, Klineberg IJ. Isokinetic exercise management of temporomandibular joint clicking in young adults. J Prosthet Dent 70: 33-39, 1993.

37. Núñez SC, Garcez AS, Suzuki SS, Ribeiro MS. Management of mouth opening in patients with temporomandibular disorders through low-level LASER therapy and transcutaneous electrical neural stimulation. Photomed LASER Surg 24: 45-49, 2006.

38. Marini I, Gatto MR, Bonetti GA. Effects of super pulsed low-level LASER therapy on temporomandibular joint pain. Clin J Pain 26: 611-616, 2010.

39. Simel A, Faruk E, Cem S. Evaluation of low-level LASER therapy in TMD patients. Case Rep Dentistry 2015.

40. Pinheiro AL, Cavalcanti ET, Pinheiro TI, Alves MJ, Manzi CT. Low power LASER therapy in the management of disorders of the maxillofacial region. J Clin LASER Med Surg 15: 181-183, 1997.

41. Petrucci A, Sgolastra F, Gatto R, Mattei A, Monaco A. Effectiveness of low-level LASER therapy in temporomandibular disorders: a systematic review and meta-analysis. J Orofac Pain 25: 298-307, 2011.

\section{APPENDIX I}

\section{THE WORLD HEALTH ORGANIZATION QUALITY OF LIFE (WHOQOL) -BREF WHOQOL-BREF}

The following questions ask how you feel about your quality of life, health, or other areas of your life. I will read out each question to you, along with the response options. Please choose the answer that appears most appropriate. If you are unsure about which response to give to a question, the first response you think of is often the best one.

Please keep in mind your standards, hopes, pleasures and concerns. We ask that you think about your life in the last four weeks.

\begin{tabular}{|l|l|l|c|c|c|c|}
\hline & & Very poor & Poor & Neither poor nor good & Good & Very good \\
\hline 1. & $\begin{array}{l}\text { How would you rate } \\
\text { your quality of life? }\end{array}$ & 1 & 2 & 3 & 4 & 5 \\
\hline & & $\begin{array}{l}\text { Very } \\
\text { dissatisfied }\end{array}$ & Dissatisfied & $\begin{array}{c}\text { Neither satisfied nor } \\
\text { dissatisfied }\end{array}$ & Satisfied & $\begin{array}{l}\text { Very } \\
\text { satisfid }\end{array}$ \\
\hline 2. & $\begin{array}{l}\text { How satisfied are you with } \\
\text { your health? }\end{array}$ & 1 & 2 & 3 & 4 & 5 \\
\hline
\end{tabular}

The following questions ask about how much you have experienced certain things in the last four weeks.

\begin{tabular}{|l|l|c|c|c|c|c|}
\hline & & Not at all & A little & $\begin{array}{l}\text { A moderate } \\
\text { amount }\end{array}$ & $\begin{array}{l}\text { Very } \\
\text { much }\end{array}$ & $\begin{array}{l}\text { An extreme } \\
\text { amount }\end{array}$ \\
\hline 3. & $\begin{array}{l}\text { To what extent do you feel that physical } \\
\text { pain prevents you from doing what you } \\
\text { need to do? }\end{array}$ & 5 & 4 & 3 & 2 & 1 \\
\hline 4. & $\begin{array}{l}\text { How much do you need any medical } \\
\text { treatment to function in your daily ife? }\end{array}$ & 5 & 4 & 3 & 2 & 1 \\
\hline 5. & How much do you enjoy life? & 1 & 2 & 3 & 4 & 5 \\
\hline 6. & $\begin{array}{l}\text { To what extent do you feel your life to be } \\
\text { meaningful? }\end{array}$ & 1 & 2 & 3 & 4 & 5 \\
\hline
\end{tabular}




\begin{tabular}{|l|l|c|c|c|c|c|}
\hline & & Not at all & A little & $\begin{array}{l}\text { A moderate } \\
\text { amount }\end{array}$ & Very much & Extremely \\
\hline 7. & $\begin{array}{l}\text { How well are you able to } \\
\text { concentrate? }\end{array}$ & 1 & 2 & 3 & 4 & 5 \\
\hline 8. & $\begin{array}{l}\text { How safe do you feel in your daily } \\
\text { life? }\end{array}$ & 1 & 2 & 3 & 4 & 5 \\
\hline 9. & $\begin{array}{l}\text { How healthy is your physical } \\
\text { environment? }\end{array}$ & 1 & 2 & 3 & 4 & 5 \\
\hline
\end{tabular}

The following questions ask about how completely you experience or were able to do certain things in the last four weeks.

\begin{tabular}{|l|l|l|c|l|l|c|}
\hline & & Not at all & A little & Moderately & Mostly & Completely \\
\hline 10. & $\begin{array}{l}\text { Do you have enough energy for } \\
\text { everyday life? }\end{array}$ & 1 & 2 & 3 & 4 & 5 \\
\hline 11. & $\begin{array}{l}\text { Are you able to accept your } \\
\text { bodily appearance? }\end{array}$ & 1 & 2 & 3 & 4 & 5 \\
\hline 12. & $\begin{array}{l}\text { Have you enough money to meet } \\
\text { your needs? }\end{array}$ & 1 & 2 & 3 & 4 & 5 \\
\hline 13. & $\begin{array}{l}\text { How available to you is the } \\
\text { information that you need in your } \\
\text { day-to-day life? }\end{array}$ & 1 & 2 & 3 & 4 & 5 \\
\hline 14. & $\begin{array}{l}\text { To what extent do you have the } \\
\text { opportunity for leisure activities? }\end{array}$ & 1 & & & 4 \\
\hline
\end{tabular}

\begin{tabular}{|l|l|l|c|c|c|c|}
\hline & & Very poor & Poor & $\begin{array}{l}\text { Neither poor } \\
\text { nor good }\end{array}$ & Good & Very good \\
\hline 15. & $\begin{array}{l}\text { How well are you able to get } \\
\text { around? }\end{array}$ & 1 & 2 & 3 & 4 & 5 \\
\hline \hline & & $\begin{array}{l}\text { Very } \\
\text { dissatisfied }\end{array}$ & Dissatisfied & $\begin{array}{l}\text { Neither } \\
\text { satisfied nor } \\
\text { dissatisfied }\end{array}$ & Satisfied & $\begin{array}{l}\text { Very } \\
\text { satisfied }\end{array}$ \\
\hline 16. & How satisfied are you with your sleep? & 1 & 2 & 3 & 4 & 5 \\
\hline 17. & $\begin{array}{l}\text { How satisfied are you with your } \\
\text { ability to perform your daily } \\
\text { living activities? }\end{array}$ & 1 & 2 & 3 & 4 & 5 \\
\hline 18. & $\begin{array}{l}\text { How satisfied are you with your } \\
\text { capacity for work? }\end{array}$ & 1 & 2 & 3 & 4 & 5 \\
\hline
\end{tabular}




\begin{tabular}{|l|l|c|c|c|c|c|}
\hline 19. & $\begin{array}{l}\text { How satisfied are you with } \\
\text { yourself? }\end{array}$ & 1 & 2 & 3 & 4 & 5 \\
\hline 20. & $\begin{array}{l}\text { How satisfied are you with your } \\
\text { personal relationships? }\end{array}$ & 1 & 2 & 3 & 4 & 5 \\
\hline 21. & $\begin{array}{l}\text { How satisfied are you with your } \\
\text { sex life? }\end{array}$ & 1 & 2 & 3 & 5 \\
\hline 22. & $\begin{array}{l}\text { How satisfied are you with the } \\
\text { support you get from your friends? }\end{array}$ & 1 & 2 & 3 & 4 & 5 \\
\hline 23. & $\begin{array}{l}\text { How satisfied are you with the } \\
\text { conditions of your living place? }\end{array}$ & 1 & 2 & 3 & 5 \\
\hline 24. & $\begin{array}{l}\text { How satisfied are you with your access } \\
\text { to health services? }\end{array}$ & 1 & 2 & 3 & 4 \\
\hline 25. & $\begin{array}{l}\text { How satisfied are you with your } \\
\text { transport? }\end{array}$ & 1 & 2 & 3 & 5 \\
\hline
\end{tabular}

The following question refers to how often you have felt or experienced certain things in the last four weeks.

\begin{tabular}{|l|l|l|l|c|c|c|}
\hline 26. & $\begin{array}{l}\text { How often do you have negative } \\
\text { feelings such as blue mood, despair, } \\
\text { anxiety, depression? }\end{array}$ & 5 & Seldom & Quite often & Very often & Always \\
\hline
\end{tabular}

\section{Do you have any comments about the assessment?}


[The following table should be completed after the interview is finished]

\begin{tabular}{|c|c|c|c|c|c|}
\hline & & \multirow{2}{*}{ Equations for computing domain scores } & \multirow[b]{2}{*}{$\begin{array}{l}\text { Raw score } \\
4-20\end{array}$} & \multicolumn{2}{|c|}{ Transformed scores* } \\
\hline & & & & $0-100 \%$ & \\
\hline 27. & $\begin{array}{l}\text { Domain } 1 \\
\text { physical health } \\
7 \text { items }\end{array}$ & $\begin{array}{c}(6-\mathrm{Q} 3)+(6-\mathrm{Q} 4)+\mathrm{Q} 10+\mathrm{Q} 15+\mathrm{Q} 16+\mathrm{Q} 17+\mathrm{Q} 18 \\
+\quad+\quad++++\end{array}$ & a. $=$ & b: & $\mathrm{c}:$ \\
\hline 28. & $\begin{array}{l}\text { Domain } 2 \\
\text { Psychological } \\
\text { health } \\
6 \text { items }\end{array}$ & $\begin{array}{l}\mathrm{Q} 5+\mathrm{Q} 6+\mathrm{Q} 7+\mathrm{Q} 11+\mathrm{Q} 19+(6-\mathrm{Q} 26) \\
++++++\end{array}$ & a. $=$ & b: & c: \\
\hline 29. & $\begin{array}{l}\text { Domain } 3 \\
\text { Social relation } \\
3 \text { items }\end{array}$ & $\begin{array}{c}\mathrm{Q} 20+\mathrm{Q} 21+\mathrm{Q} 22 \\
+\quad+\end{array}$ & a. $=$ & b: & $\mathrm{c}:$ \\
\hline 30. & $\begin{array}{l}\text { Domain } 4 \\
\text { Environmental } \\
8 \text { items }\end{array}$ & $\begin{array}{l}\mathrm{Q} 8+\mathrm{Q} 9+\mathrm{Q} 12+\mathrm{Q} 13+\mathrm{Q} 14+\mathrm{Q} 23+\mathrm{Q} 24+\mathrm{Q} 25 \\
++++++\end{array}$ & a. $=$ & b: & c: \\
\hline
\end{tabular}

After summation of scores in to row scores that ranges from 4- 20 that will be later

Converted in to percentage ranges from $0-100 \%$ 